\title{
Research Paper: One Year Survival and Quality of Life in Patients Successfully Discharged From Neuro Critical Care $\underbrace{}_{\text {crosslark }}$ Unit
}

\author{
Maryam Poursadeghfard ${ }^{1}$, Kamal Bastani², Tahereh Poursadeghfard ${ }^{3}$, Sina Karamimagham $^{4}$, Sadegh Izadi $^{1 *}$ \\ 1. Clinical Neurology Research Center, School of Medicine, Shiraz University of Medical Sciences, Shiraz, Iran. \\ 2. Department of Neurology, School of Medicine, Shiraz University of Medical Sciences, Shiraz, Iran. \\ 3. Department of Statistics and Mathematics, Firuzabad branch, Islamic Azad University, Firuzabad, Iran. \\ 4. Department of Pediatrics, School of Medicine, Fasa University of Medical Sciences, Fasa, Iran.
}

Article info:

Received: 20 Jan. 2017

Accepted: 01 May 2017

\section{Keywords:}

Intensive care unit, Survival, Quality of life
Crtation: Poursadeghfard M, Bastani K, Poursadeghfard T, Karamimagham S, Izadi S. One Year Survival and Quality of Life in Patients Successfully Discharged From Neuro Critical Care Unit. Iranian Rehabilitation Journal. 2017; 15(3):249-258. https:// doi.org/10.29252/NRIP.IRJ.15.3.249

https://doi.org/10.29252/NRIP.IRJ.15.3.249

\begin{abstract}
Objectives: Neuro-critical Intensive Care Units (NICUs) have functioned to deliver intensive medical care services for patients with acute neurology problems. However, physicians and ICU staff do not have any feedback about their patients and their abilities after successful discharge. Various studies have documented short-term survival in ICUs, but the long-term outcome and quality of life (QOL) are less studied.
\end{abstract}

Methods: This is a retrospective cohort study over a period of one year from February 2011 to February 2012 (Shiraz, South of Iran). Patients' charts were used to collect the data. Survival and QOL after one year following NICU admission were assessed for surviving patients by a telephone interview with patients or their family members using Karnofsky Performance Scale (KPS).

Results: Out of 93 patients, 42(45.2\%) were male, and 51(54.8\%) were female. Malignant ischemic stroke (34\%) was the most common cause followed by Guillain Barre Syndrome (21\%). Among the living successfully discharged patients, $45 \%$ were able to perform normal activity and work without any special assistance. The patients who were unable to work were $28 \%$, but they were able to live at home and care for their most personal needs. The patients who were unable to care for themselves were $3 \%$ and required institutional or hospital care. Over one year following discharge, $24 \%$ patients were passed away.

Discussion: is lower in NICU survivors compared with general population; however, if patients' selection and out of hospital care are done appropriately and continuously, more patients can live independently or even come back to their work. Indeed, it is important to identify patients who benefit more from NICU during decision making for ICU admission. As a result, more efficient rehabilitation could be achieved in the future. However, our conclusions are only related to our ward and do not apply to the total population of critical neurology patients. 


\section{Introduction}

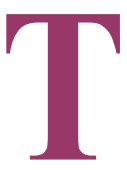

he major target of health care system is to decrease mortality and morbidity and increase the ability to return to daily activities while maintaining functional status [1]. For this reason, Intensive Care Units (ICUs) were specialized for acutely ill patients with the reversible condition. These units offer special treatments that are not routinely available in non-ICU wards [2].

During last decades, Neuro-critical Intensive Care Units (NICUs) have functioned as a sub-specialized ICU to deliver intensive medical care services for patients with acute neurology problems (stroke, status epilepticus, Guillain-Barre syndrome, myasthenic crisis). However, physicians and ICU staff do not have any feedback about their patients and their abilities after successful discharge [3], and there is no valid data on longterm survival and Quality of Life (QOL) in this group of patients [4]. Many studies have documented short-term survival in ICUs, such as successful recovery and discharged from hospital after ICU admission, but the longterm outcome and QOL are less studied as compared to short-term in the literature [5].

In spite of bed limitation, sometimes the best selection of patients who are a candidate for admitting to ICU does not occur. For example, intensive care for patients with Cerebro-Vascular Accident (CVA) is going to be a routine these days. Do they have a better survival in the ICU? For a group of physicians, the usefulness of ICU after a catastrophic brain event is controversial [6], and some other doubt about the effectiveness of ICU for very old patients [7].

In most parts of the world (including our center), ICU beds are limited, and they cost more than bed in other wards. Therefore, the best selection of the patients is critical, and it is necessary to know about the burden of treatment in ICU, long-term outcome, and QOL after ICU discharge [8]. This survey aimed to study the survival and QOL in patients admitted to NICU in Nemazee Hospital, Shiraz, South of Iran. We speculate that the results of this study will help us to know long-term mortality and morbidity of our patients in NICU and it would be a guide for better decision and patient selection in this critical ward. As a result, more efficient rehabilitation could be achieved in the future.

\section{Methods}

This is a retrospective cohort study in a limited time. We enrolled all patients admitted to NICU in Nemazee Hos- pital, Shiraz, south of Iran (an educational center) over a period of one year (February 2011-February 2012). Nemazee Hospital has multiple subspecialty ICUs as internal medicine, neurology, neurosurgery, general surgery, trauma, neonatal, and pediatric. This hospital also has a newly established ICU in the emergency ward with 15 beds that take care of critical patients in all of the medical fields in the emergency room.

Many neurocritical patients receive medical care in this ward; however, the rest of the patients are transferred to the NICU. Our NICU is a subspecialty neurology ward with four beds that provides care to all non-sugary neurology patients. Inclusion criteria for NICU care require ventilator support, unstable cardiovascular state, progressive decrease in the consciousness level, and patients who received recombinant tissue plasminogen activator (rtPA). According to a regional protocol, patients with subarachnoid hemorrhage $(\mathrm{SAH})$, brain tumor, and intracranial hemorrhage (ICH), who need neurosurgery intervention, and also patients with traumatic brain injury are admitted to the neurosurgery ICU and patients treated non-surgically are referred to our ICU. Also, patients with intoxication or poisoning receive their care in internist ICU. Patients with Glasgow Coma Scale (GCS) 3 and potentially terminal illnesses such as end-stage of cancers do not enter NICU.

We collected the patients' information recorded in a hand-written NICU database (name, sex, chart number, date of admission and discharge, death or transfer to the ward and phone number). Patients' charts were collected to complete the data. After determining the in-hospital mortality rate in this year, each patient who was discharged from NICU was evaluated for basic functional state and QOL before admission. All patients with abnormal prehospital functional state related to a current disease were excluded.

We chose the patients who were functionally normal or did not have previously related symptoms at the time of enrollment. Initially, demographic data (age, sex), diagnosis during admission in NICU, previous functional state, and the number of patients who died during hospital course were recorded in a questionnaire. Survival and QOL after one year following NICU admission were assessed for surviving patients by a telephone interview with patients or their family members using Karnofsky Performance Scale (KPS). This scale has proven as a valuable tool to perform measurement of and comparison between the functional statuses of individual patients [9].

This scale is a numerical definition rating criteria (as a percent) and consists of 0 to 100 numbers. The indicative 
of death is 0 , and the normal condition is 100 . Patients who get a score between these ranges have different levels of disability (appendix 1). Before interviewing all the patients or their family, they were informed about the survey. A neurology resident took the interview and informed the subjects. This observational study is approved by University ethics committee.

\section{Statistical methods}

SPSS v.16.0 software package (SPSS Inc, Chicago, Illinois) was used for statistical analysis. The factors investigated were gender, age, past medical history, diagnosis on admission, in/out hospital mortality rate, and KPS after one year. Continuous variables were described by mean with their Standard Deviation (SD) and categorical variables by numbers and percentage appropriately. $95 \%$ confidence interval was supposed for any estimated prevalence. Comparison between groups was done by Student's t-test, ANOVA, Chi-Square test, and Kruskal Wallis test as appropriate. The significance level was set at 0.05 or less $(\mathrm{P} \leq 0.05)$.

\section{Results}

During one year 93 patients were admitted to NICU. Out of total $42(45.2 \%)$ patients were male and 51(54.8\%) patients were female. The age range was $18-88$ years with a mean of 50.46 (SD 19.876). Out of total 93 patients, 23 died in hospital before discharging, 15 women and eight men. In-hospital mortality rate was $24.73 \%$. All patients were discharged successfully, and we would contact them accepted to take part in the interview. However, we were not able to contact three patients after one year because of change in their address or phone number. Out of 67 patients who were followed, 16 died over one year, and 51 patients were alive in the follow-up (Figure
1). Patients with stroke were the most population who had in and out- hospital mortality (58\%).

We divided admitted patients into 3 age groups: $<45$ years, between 45 and 65 years, and $>65$ years. The first group had the most $(45.2 \%)$, and the third group had the least $(25.8 \%)$ number of the patients (Figure 2). From variable causes of NICU admission, malignant ischemic CVA (34\%) was shown to be the most common cause followed by Guillain Barre Syndrome (GBS) (21\%) (Table 1).

The mean KPS for total 67 patients discharged from NICU was 54.93(37.794) with a minimum of 0 and a maximum of 100 [95\% CI $(45.71,64.14)]$. Among the living patients successfully discharged, $45 \%$ were able to carry on normal activity and to work without any need of special assistance (KPS 80, 90 and 100). Patients who were unable to work was $28 \%$, but they were able to live at home and care for their most personal needs with varying amounts of assistance requirements (KPS 50, 60 and 70). 3\% were unable to care for themselves and required institutional or hospital care (KPS 10, 20, 30 and 40). Over one year following discharge (KPS 0) (out of hospital mortality rate) $24 \%$ were passed away.

From the patients who were alive, MG (KPS 95) and ADEM (KPSS 90) had the best and ischemic CVA (KPS 28) had the worse outcome (Figure 3). Etiology was a significant indicator for poor performance $(\mathrm{P}<0.032)$. Regarding the sex, the mean KPS for men was 36.59(38.962) [95\% CI $(24.81,48.37)]$ and for women, it was 44.49 (41.786) [95\% CI $(33.02,55.96)]$. Women had a better performance than men after one year $(\mathrm{P}<0.00)$.

The age group analysis showed that the younger the patients, the better KPSs. All patients who were under

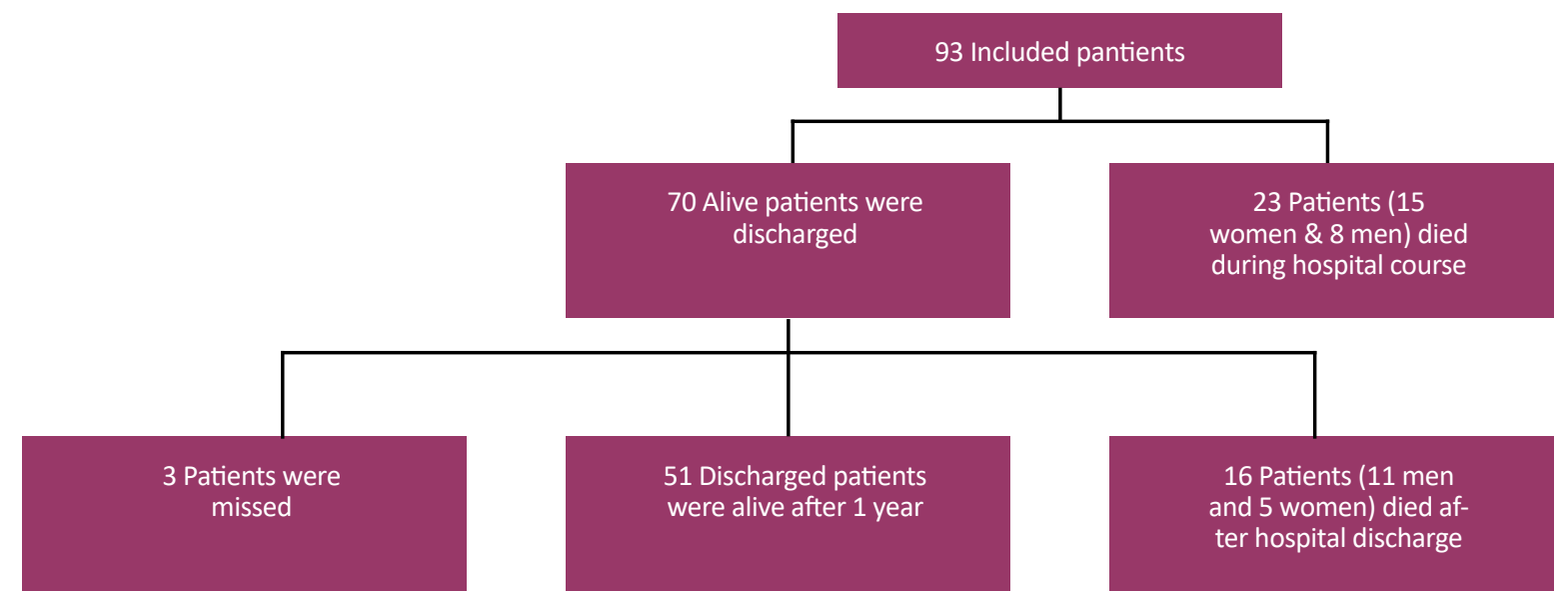

Figure 1. Flowchart of the patients admitted to NICU and followed after one year 


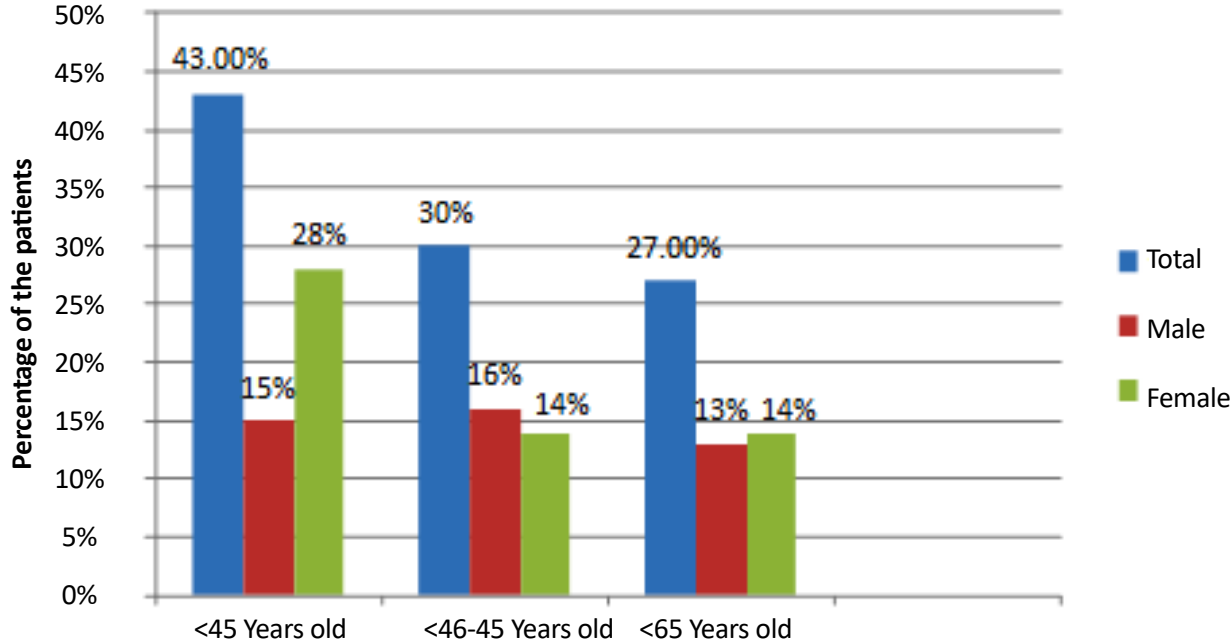

Figure 2. The patients' percentage according to sex

Dranlan Rehabontration Journa

66 years had a better mean KPS compared with the older patients $(\mathrm{P}=0.00)$, but there was no significant difference between the patients who were younger than 45 years and between 45 and 65 years (the first and the second group) $(\mathrm{P}=0.262)$. The mean KPS according to age group are shown in Table 2.

\section{Discussion}

In this study, for the first time, we evaluated the longterm outcome in critically ill patients admitted in a regional NICU that could be a starting point for improving the critical care system in this area. However, it is essential to remind that our conclusions are only re-

Table 1. Number, KPS and mortality of patients discharged from NICU according to diagnosis

\begin{tabular}{ccccccccc}
\hline DX & $\begin{array}{c}\text { Admitted } \\
\text { Patients (\%) }\end{array}$ & $\begin{array}{c}\text { Followed } \\
\text { Patients }\end{array}$ & $\begin{array}{c}\text { Min } \\
\text { KPS }\end{array}$ & $\begin{array}{c}\text { MAX } \\
\text { KPS }\end{array}$ & $\begin{array}{c}\text { Mean } \\
\text { KPS }\end{array}$ & SD & Cl & $\begin{array}{c}\text { Mortality } \\
\text { Rate (\%) }\end{array}$ \\
\hline CVA ischemic & $32(34)$ & $22(32.8)$ & 0 & 100 & 28.18 & 31.265 & $95(14.32,42.04)$ & 58 \\
\hline ICH & $14(15)$ & $10(14.9)$ & 0 & 100 & 59 & 37.253 & $95(32.35,85.65)$ & 10.5 \\
\hline CSVT & $6(6.6)$ & $3(4.4 \%)$ & 50 & 100 & 80 & 26.458 & $95(14.28,145.72)$ & 5.3 \\
\hline GBS & $20(21)$ & $16(23.9)$ & 0 & 100 & 67.5 & 36.606 & $95(47.99,87.01)$ & 15.6 \\
\hline MG & $4(4.5)$ & $4(6)$ & 90 & 100 & 95 & 5.774 & $95(85.81,104.19)$ & 0 \\
\hline $\begin{array}{c}\text { Complicated } \\
\text { brain tumor }\end{array}$ & $1(1.1)$ & $1(1.5)$ & 0 & 0 & 0 & - & - & 5.3 \\
\hline $\begin{array}{c}\text { Degenerative } \\
\text { disease }\end{array}$ & $2(2.2)$ & $2(3)$ & 50 & 80 & 65 & 21.213 & $95(-125.59,255.59)$ & 0 \\
\hline SE & $10(11.2)$ & $5(7.5)$ & 0 & 90 & 66 & 37.148 & $95(19.87,112.13)$ & 5.3 \\
\hline ADEM & $1(1.1)$ & $1(1.5)$ & 90 & 90 & 90 & - & & 0 \\
\hline PRES & $2(2.2)$ & $2(3)$ & 50 & 90 & 70 & 28.284 & $95(-184.12,324.12)$ & 0 \\
\hline MS & $1(1.1)$ & $1(1.5)$ & 80 & 80 & 80 & - & & 0 \\
\hline Total & $93(100)$ & $67(100)$ & 0 & 100 & 54.93 & 37.794 & $95(45.71,64.14)$ & 100 \\
\hline
\end{tabular}

Mranlan Rehabonllation Journa

CVA: Cerebro Vascular Accident; ICH: Intra-Cranial Hemorrhage; CSVT: Cerebral Sinus Venous Thrombosis; GBS: Guillaine Barre Syndrome; MG: Myasthenia Gravis; SE: Status Epilepticus; ADEM: Acute Demyelinating Encephalo Myelopathy; PRES: Posterior Reversible Encephalopathy Syndrome; MS: Multiple Sclerosis 


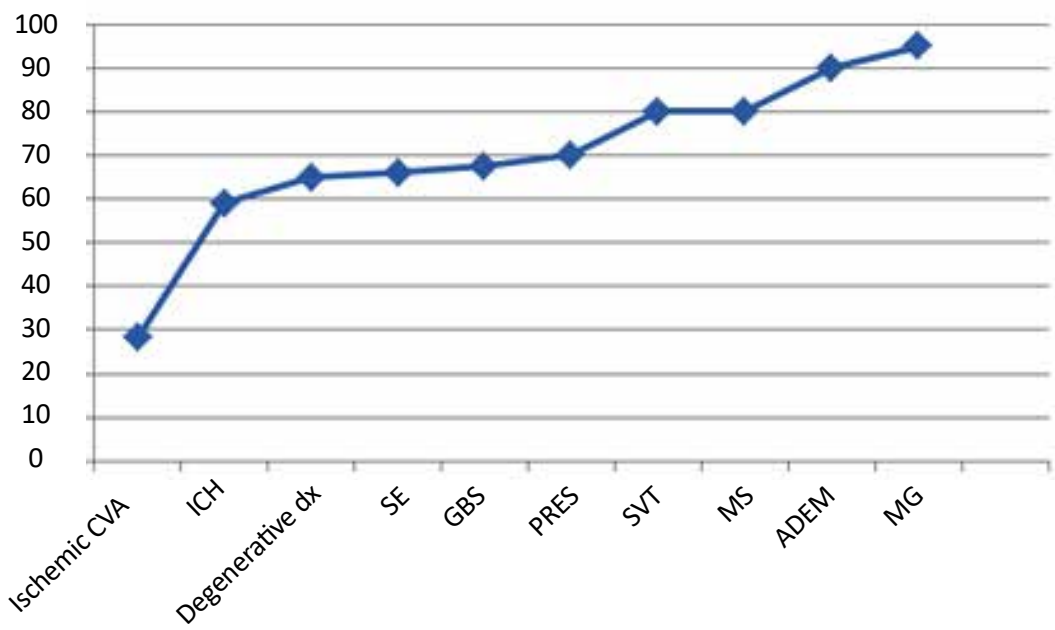

Figure 3. The mean KPS regarding the etiology

IIranlan Rkhabolltation Journal

lated to our ward and do not apply to the total population of critical neurology patients. In this study, women were admitted more frequently than men $(54.8 \%$ compared with $45.2 \%$ ) and it was more considerable among patients younger than 45 years old (28 female patients versus 14 male patients).

They also had more in-hospital mortality, with a female to male mortality ratio of $1.87: 1$. There are some recent data about higher non-ICU admission and mortality in critically ill female patients especially those who are older than 50 years. However, with increasing age, ICU admission is seen more among men [10]. In the study performed by Fowler and coworkers showed that although elderly males have a higher rate of death after hospital admission, in critically ill patients women are more prone to death than men of similar age [11].

Other reports have shown sex differentiation outcome is based on etiology; for example, one study reported no differences between sex outcomes in surgical ICUs, although sepsis increased the death rate in females [12, 13]. According to above studies, the reasons for higher mortality in women during critical states, despite pro- tective role of estrogen on cardiovascular and immune systems, have been poorly studied. However, it seems that sex differences in pharmacokinetics, susceptibility to immunological disorders, unique cytokine responses, and sex-related hormone level may explain this results.

Some studies have postulated better access to health care, and better pre-morbid health state for men might support them during critical medical condition [10-13]. In this study, fewer numbers of patients were older than 65 years $(25.8 \%)$; it may be due to age-related effect for ICU care. In contrast, young patients were the majority $(45.2 \%)$. An overview of literature shows that the elderly patients are selected less for intensive care and the likelihood of ICU admission especially after 85 years is decreased. While the intensive care beds are limited in most hospitals, diagnosis, and end life care are the most important factors influencing decision-making for intensive care $[14,15]$. This study might represent the fact that more selection had been done for younger patients with more treatable causes.

In different medical fields, ICU mortality highly depends on the cause of the admission and severity of the

Table 2. KPS of patients admitted to NICU according to age group

\begin{tabular}{ccccccc}
\hline Age Group & $\begin{array}{c}\text { Patients } \\
\text { Number }\end{array}$ & $\begin{array}{c}\text { Minimum } \\
\text { KPS }\end{array}$ & $\begin{array}{c}\text { Maximum } \\
\text { KPS }\end{array}$ & $\begin{array}{c}\text { Mean } \\
\text { KPS }\end{array}$ & SD & Cl \\
\hline$<45$ years & 32 & 0.00 & 100 & 68.75 & 34.52 & $95(56.30,81.2)$ \\
\hline $45-65$ years & 22 & 0.00 & 100 & 58.64 & 33.42 & $95(43.82,73.45)$ \\
\hline 65 years & 13 & 0.00 & 50 & 14.62 & 22.95 & $95(0.74,28.49)$ \\
\hline Total & 67 & 0.00 & 100 & 54.93 & 37.79 & $95(45.7,64.14)$ \\
\hline
\end{tabular}

Mrantan Rehabonltation Journal 
disease. One study indicates that $6.4 \%$ to $40 \%$ death occur among critically ill patients in ICUs [16]. In two large multicenter studies, ICU mortality was estimated $12.4 \%$ in 38,000 and $16.6 \%$ in 17,000 patients [17]. One of the main factors determining mortality in ICU has been reported to be advanced age; however, other factors as a cardiac state, lower mean arterial blood pressure, and tachycardia on admission time have been marked [18]. Furthermore, team communication strategies and a lower bed-to-nurse ratio have been reported as significant factors resulting in lower ICU mortality in one study among 69 ICUs in the United States [19].

In-hospital mortality of our ICU was $24.73 \%$. We think it is a little high and this proportion of mortality during admission time could be related to underlying causes and severity of critical situations. Most of our patients referred to NICU had malignant ischemic CVA (34\%). Patients with malignant type of stroke (with carotid or middle cerebral artery occlusion) are assigned to ICU when they are prone to severe brain edema or structural shifting and need for decompressive surgery. These patients have a poorer prognosis and higher mortality. Moreover, stroke increases parallel with age; this causes the fewer favorites outcome. On the contrary, patients with a better outcome such as MG, MS, PRES, and ADEM had fewer admissions in our NICU. So more advanced age and malignant causes among our patients may be the main explanation for our mortality rate.

With improving intensive care for critically ill patients, it is logical to produce outcome measures by each health care system which could help patients' outcome and reduce the burden of care [20]. Beyond the mortality which is a short-term outcome scale, other factors such as QOL, especially when they are evaluated during the long-term follow-up, could be a better indicator of prognosis. QOL among survivors, will represent a global aspect of health status. Many of the studies about intensive care have focused on hospital course and mortality. However, to evaluate the effectiveness and efficiency of care, it is essential to evaluate the patients and their QOLs beyond the hospital course.

As to this fact for long-term outcome evaluation, we focused not only on death rate but also on incorporate QOL. It is assumed that QOL is less optimal in critically ill patients than their matched population, but it could improve over the years [21]. One systematic review of QOL in 7,320 ICU survivors demonstrated ow QOL for all aspects of health at baseline and 6 months to 14 years after discharge [22]. Our results showed that in total population physical scores for QOL after one year had been low compared to the general population (mean KPS=54.93).

Following successful discharge, $45 \%$ of patients were in a good functional state with no need for special assistance (KPS 80, 90, and 100). 42\% were able to perform personal activity and needed some varying degrees of support. Only 3\% of patients required special care (KPS 10, 20, 30, and 40). Therefore, most of the patients were living independently or needed minimal support and were able to do most personal needs. We speculate that it may have two reasons. First, as this study showed both in-hospital and out-hospital mortality occurred in more severe cases (mostly ischemic CVA), these patients have a limited capacity of complete recovery, whereas other diseases without neuronal involvement may not have this limitation.

Therefore, if patients were discharged successfully, and survived after one year, they had less severe underlying disease with the more acceptable outcome. Second, the number of our sub-special ICU beds is limited (just four beds apart from other special ICU beds in the hospital); therefore, it is preferred to prioritize the critically ill patients with potent reversible causes during the patients' referral to NICU. After ischemic CVA that was the most common indication of critical care, more reversible causes (SE, ICH, GBS) were common diseases in our NICU; patients with these group of diseases usually could return to near normal life if they are given a suitable care in and out of the hospital. This result is also seen in other studies. For example, in a study conducted in $2004,58 \%$ of 173 patients could come back to equivalent employment after one year [23].

The minority of our patients (3\%) who were alive after one year had a severe disability and needed equivalent institutional care. Some other studies have reported the opposite though. On the other hand, their survivors required notable supportive care after the serious illness [24]. One study conducted by Covinsky and colleagues in 1994 showed that one-third of critically ill patients had required care-giving support during 12 months following discharge [25].

Another study conducted by Swoboda and Colleagues in 2002 demonstrated that $60 \%$ of patients in the general surgery ICU had received a moderate to high degree of care by their family between 1 and nine months after a prolonged illnesses and $44.9 \%$ had to quit the work after one month [26]. In one survey on informal caregiver burdens in 2007, an average of 6 hours of patient's assistance among 24 hours has been reported [27]. This discrepancy 
in results could be due to different types of patients and their problems (surgical versus medical), the patients' selection policy, ICU complications, and duration of ICU stay, all being different from hospital to hospital.

Mortality during one-year follow-up was $24 \%$ and more prevalent in the poor physical state $(58 \%$ in patients with stroke). Malignant underlying causes and long-term disabilities (MCA infarction, brain tumor, etc.), which result in a poor outcome, may be the main reason. Patients with ischemic CVA usually have adjacent co-morbid diseases and predisposing factors such as diabetes, hypertension, and heart failure that impact their outcome and mortality [28-30]. Furthermore, these physically disabled patients are more prone to stroke complications, recurrent stroke and recurrent trauma which enhance the risk of death.

In a study conducted by Loor et al. showed that impaired swallowing and incontinence, a severity marker of stroke were associated with mortality during one month after stroke. Indeed recurrent falling and the femoral fracture was the reason of mortality in $8 \%$ of their patients [31]. Challenging condition and poor care-giving after discharge could be another reason. More recently, the trend has gone hopefully toward the continuity of care for seriously ill patients after ICU care and hospitalization. It has profound effects on their outcomes [32].

In contrast to ischemic stroke, we had good results with SE, PRES, MG, and ADEM; they mostly came back to an acceptable range of daily activity or equivalent employment although the number of these patients was not enough to have a careful assessment.

This study has some methodological limitations: Limited time of retrospective cohort study. We recommend a large cohort study with regular periodical follow-up to achieve a more reliable conclusion; A short period of follow-up. Long-term assessment of QOL after critical care could be more ideal; Focusing mainly on physical disability. Cognitive and mental evaluation is one of the important aspects of patients' assessment after critical care; While we gathered the data by phone interview, its reliability may be affected; Few beds and a small number of patients which may not reflect a global aspect of NICU outcome. A multicenter study with more number of neurology patients is recommended.

\section{Conclusion}

Many factors (age, sex, co-morbid diseases, and previous health state) could affect the outcome in NeuroCritical Intensive Care Unit. Although there is a signifi- cant improvement in managing of critically ill patients in ICU, some of them, especially patients with notably permanent neuronal damage, may not benefit from it anymore. In contrast, diseases such as $\mathrm{MG}, \mathrm{ADEM}$, and PRES which do not destroy the neurons permanently show a good outcome. Therefore, it is important to identify patients who benefit more from NICU during decision making for ICU admission.

QOL is lower in NICU survivors compared with general population, and different patients need support, but if patients' selection and out-of-hospital care are done appropriately and continuously, more patients can live independently or even come back to their work. These facts are raised from our study, and these cannot be applied to the whole population of critically ill patients.

\section{Acknowledgements}

This research did not receive any specific grant from funding agencies in the public, commercial, or not-forprofit sectors. The authors would like to thank Dr. Nasrin Shokrpour at Center for Development of Clinical Research of Nemazee Hospital for editorial assistance.

\section{Conflict of Interest}

The authors declared no conflicts of interest.

\section{References}

[1] García Lizana F, Peres Bota D, De Cubber M, Vincent JL. Long term outcome in ICU patients: What about quality of life. Intensive Care Medicine. 2003; 29(8):1286-93. doi: 10.1007/s00134-003-1875-z

[2] Korošec Jagodič H, Jagodič K, Podbregar M. Long term outcome and quality of life of patients treated in surgical intensive care: A comparison between sepsis and trauma. Critical Care. 2006; 10(5):R134. doi: 10.1186/cc5047

[3] Vasilevskis EE, Kuzniewicz MW, Cason BA, Lane RK, Dean ML, Clay T, et al. Predictors of early postdischarge mortality in critically ill patients: A retrospective cohort study from the California Intensive Care Outcomes project. Journal of Critical Care. 2011; 26(1):65-75. doi: 10.1016/j.jcrc.2010.06.010

[4] Kiphuth IC, Schellinger PD, Köhrmann M, Bardutzky J, Lücking H, Kloska S, et al. Predictors for good functional outcome after neurocritical care. Critical Care. 2010; 14(4):R136. doi: $10.1186 /$ cc9192

[5] Jeitziner MM, Hantikainen V, Conca A, Hamers JP. Longterm consequences of an intensive care unit stay in older critically ill patients: Design of a longitudinal study. BMC Geriatrics. 2011; 11(1):52. doi: 10.1186/1471-2318-11-52 
[6] Riachy M, Sfeir F, Sleilaty G, Hage Chahine S, Dabar G, Bazerbachi T, et al. Prediction of the survival and functional ability of severe stroke patients after ICU therapeutic intervention. BMC Neurology. 2008; 8(1):24. doi: 10.1186/1471-2377-8-24

[7] Sacanella E, Pérez Castejón JM, Nicolás JM, Masanés F, Navarro M, Castro P, et al. Functional status and quality of life 12 months after discharge from a medical ICU in healthy elderly patients: A prospective observational study. Critical Care. 2011; 15(2):R105. doi: 10.1186/cc10121

[8] Ho KM, Knuiman M, Finn J, Webb SA. Estimating long term survival of critically Ill patients: The PREDICT model. PLoS ONE. 2008; 3(9):e3226. doi: 10.1371/journal.pone.0003226

[9] Péus D, Newcomb N, Hofer S. Appraisal of the Karnofsky Performance Status and proposal of a simple algorithmic system for its evaluation. BMC Medical Informatics and Decision Making. 2013; 13(1). doi: 10.1186/1472-6947-13-72

[10] Lipes J, Mardini L, Jayaraman D. Sex and mortality of hospitalized adults after admission to an intensive care unit. American Journal of Critical Car. 2013; 22(4):314-9. doi: $10.4037 /$ ajcc2013225

[11] Fowler RA, Sabur N, Li P, Juurlink DN, Pinto R, Hladunewich MA, et al. Sex and age based differences in the delivery and outcomes of critical care. Canadian Medical Association Journal. 2007; 177(12):1513-9. doi: 10.1503/cmaj.071112

[12] Eachempati SR. Gender based differences in outcome in patients with sepsis. Archives of Surgery. 1999; 134(12):1342 doi: 10.1001/archsurg.134.12.1342

[13] Nachtigall I, Tafelski S, Rothbart A, Kaufner L, Schmidt $\mathrm{M}$, Tamarkin A, et al. Gender related outcome difference is related to course of sepsis on mixed ICUs: A prospective, observational clinical study. Critical Care. 2011; 15(3):R151. doi: $10.1186 /$ cc10277

[14] Yu W, Ash AS, Levinsky NG, Moskowitz MA. Intensive care unit use and mortality in the elderly. Journal of General Internal Medicine. 2000; 15(2):97-102. doi: 10.1046/j.15251497.2000.02349.x

[15] Cher DJ. Method of medicare reimbursement and the rate of potentially ineffective care of critically III patients. Journal of the American Medical Association. 1997; 278(12):1001. doi: 10.1001/jama.1997.03550120061034

[16] Mayr VD, Dünser MW, Greil V, Jochberger S, Luckner G, Ulmer $\mathrm{H}$, et al. Causes of death and determinantsof outcome in critically ill patients. Critical Care. 2006; 10(6):R154. doi: $10.1186 /$ cc5086

[17] Young MP, Birkmeyer JD. Potential reduction in mortality rates using an intensivist model to manage intensive care units. Effective Clinical Practice. 2000; 3(6):284-9. PMID: 11151525

[18] Visser P, Harriss LR, Hart GK, Bohensky M, Sundaresan L, Kennedy M. Factors involved in intensive care unit mortality following medical retrieval: Identifying differences between intensive care unit survivors and non survivors. Emergency Medicine Australasia. 2013; 25(3):260-7. doi: 10.1111/1742 6723.12075

[19] Checkley W, Martin GS, Brown SM, Chang SY, Dabbagh $\mathrm{O}$, Fremont RD, et al. Structure, process, and annual ICU mortality across 69 centers. Critical Care Medicine. 2014; 42(2):344-56. doi: 10.1097/ccm.0b013e3182a275d7
[20] Martinez EA, Donelan K, Henneman JP, Berenholtz $\mathrm{SM}$, Miralles $\mathrm{PD}$, Krug $\mathrm{AE}$, et al. Identifying meaningful outcome measures for the intensive care unit. American Journal of Medical Quality. 2014; 29(2):144-52. doi: $10.1177 / 1062860613491823$

[21] Oeyen SG, Vandijck DM, Benoit DD, Annemans L, Decruyenaere JM. Quality of life after intensive care: A systematic review of the literature. Critical Care Medicine. 2010 38(12):2386-400. doi: 10.1097/ccm.0b013e3181f3dec5

[22] Dowdy DW, Eid MP, Sedrakyan A, Mendez Tellez PA, Pronovost PJ, Herridge MS, et al. Quality of life in adult survivors of critical illness: A systematic review of the literature. Intensive Care Medicine. 2005; 31(5):611-20. doi: 10.1007/ s00134-005-2592-6

[23] Cuthbertson BH, Scott J, Strachan M, Kilonzo M, Vale L. Quality of life before and after intensive care. Anaesthesia 2005; 60(4):332-9. doi: 10.1111/j.1365-2044.2004.04109.x

[24] Griffiths J, Hatch RA, Bishop J, Morgan K, Jenkinson C, Cuthbertson $\mathrm{BH}$, et al. An exploration of social and economic outcome and associated health related quality of life after critical illness in general intensive care unit survivors: a 12 month follow-up study. Critical Care. 2013; 17(3):R100. doi: $10.1186 /$ cc12745

[25] Covinsky KE, Goldman L, Cook EF, Oye R, Desbiens N, Reding D, et al. The impact of serious illness on patients' families. Journal of the American Medical Association (JAMA). 1994; 272(23):1839-44. doi: 10.1001/jama.272.23.1839

[26] Swoboda SM, Lipsett PA. Impact of a prolonged surgical critical illness on patients' families. American Journal of Critical Care. 2002; 11(5):459-66.

[27] Van Pelt DC, Milbrandt EB, Qin L, Weissfeld LA, Rotondi AJ, Schulz R, et al. Informal caregiver burden among survivors of prolonged mechanical ventilation. American Journal of respiratory and critical care medicine. 2007; 175(2):167-73 doi: $10.1164 / \mathrm{rccm} .200604-493$ oc

[28] Romero JR, Morris J, Pikula A. Review: Stroke prevention modifying risk factors. Therapeutic Advances in Cardiovascular Disease. 2008;2(4):287-303. doi:10.1177/1753944708093847

[29] Bronnum Hansen H, Davidsen M, Thorvaldsen P. Longterm survival and causes of death after stroke. Stroke. 2001; 32(9):2131-6. doi: 10.1161/hs0901.094253

[30] Arbin M, Britton M, Faire U. Mortality and recurrences during eight years following stroke. Journal of Internal Medicine. 1992; 231(1):43-8. doi: 10.1111/j.1365-2796.1992.tb00497.x

[31] Loor HI, Groenier KH, Limburg M, Schuling J, Meyboom de Jong B. Risks and causes of death in a community based stroke population: 1 month and 3 years after stroke. Neuroepidemiology. 1999; 18(2):75-84. doi: 10.1159/000069410

[32] Nguyen YL, Wunsch H, Angus DC. Critical care: The impact of organization and management on outcomes. Current Opinion in Critical Care. 2010; 16(5):487-92. doi: 10.1097/ mcc.0b013e32833d9180 
Appendix 1.The Karnofsky Performance Scale

Requires occasional assistance, but is able to care for most personal needs 
